\title{
Dietary Medium-Chain Triglycerides Attenuate Hepatic Lipid Deposition in Growing Rats with Protein Malnutrition
}

\author{
Masashi Kuwahata $^{1}$, Hiroyo Kubota ${ }^{1}$, Saki Amano ${ }^{2}$, Meiko YoKoyama ${ }^{1}$, \\ Yasuhiro SHIMAMURA ${ }^{1}$, Shunsuke ITO ${ }^{1}$, Aki OGAWA ${ }^{1}$, Yukiko KOBAYASHI ${ }^{1}$, \\ Ken-ichi МIYAмOTO ${ }^{2}$ and Yasuhiro KIDO ${ }^{1}$ \\ ${ }^{1}$ Department of Nutrition Science, Graduate School of Life and Environmental Sciences, \\ Kyoto Prefectural University, Shimogamo, Kyoto 606-8522, Japan \\ ${ }^{2}$ Department of Molecular Nutrition, Institute of Health Biosciences, University of \\ Tokushima Graduate School, Tokushima 770-8503, Japan
}

(Received August 9, 2010)

\begin{abstract}
Summary The objective of this study was to investigate the effects of dietary mediumchain triglycerides (MCT) on hepatic lipid accumulation in growing rats with protein malnutrition. Weaning rats were fed either a low-protein diet (3\%, LP) or control protein diet $(20 \%, \mathrm{CP})$, in combination with or without MCT. The four groups were as follows: CP-MCT, $\mathrm{CP}+\mathrm{MCT}$, $\mathrm{LP}-\mathrm{MCT}$, and $\mathrm{LP}+\mathrm{MCT}$. Rats in the $\mathrm{CP}-\mathrm{MCT}$, $\mathrm{CP}+\mathrm{MCT}$ and $\mathrm{LP}+\mathrm{MCT}$ groups were pair-fed their respective diets based on the amount of diet consumed by the LP-MCT group. Rats were fed each experimental diet for $30 \mathrm{~d}$. Four weeks later, the respiratory quotient was higher in the LP-MCT group than those in the other groups during the fasting period. Hepatic triglyceride content increased in the LP groups compared with the CP groups. Hepatic triglyceride content in the LP+MCT group, however, was significantly decreased compared with that in the LP-MCT group. Levels of carnitine palmitoyltransferase (CPT) 1a mRNA and CPT2 mRNA were significantly decreased in the livers of the $\mathrm{LP}-\mathrm{MCT}$ group, as compared with corresponding mRNA levels of the other groups. These results suggest that ingestion of a low-protein diet caused fatty liver in growing rats. However, when rats were fed the low-protein diet with MCT, hepatic triglyceride deposition was attenuated, and mRNA levels encoding CPT1a and CPT2 were preserved at the levels of rats fed control protein diets.
\end{abstract}

Key Words fatty liver, protein malnutrition, medium-chain triglycerides, growing rats

Fatty liver is a common feature of children with protein malnutrition (1). Despite extensive research, the pathogenic factors that cause children to develop a fatty liver in response to protein malnutrition remain unclear. Although hepatic lipid deposition is enhanced, children with protein malnutrition display low serum lipid levels. The origin of these low serum lipid levels is generally accepted to involve a decrease in very lowdensity lipoprotein (VLDL) apolipoprotein synthesis (2$4)$. Conversely, recent studies have shown that significant lipid deposition in livers of children with severe malnutrition is not associated with impaired synthesis of VLDL apolipoprotein (5) and children with protein malnutrition exhibit fatty acid oxidation rates that are lower in the malnourished stage than the recovering and well-nourished stages (6).

Long-chain triglycerides (LCT) and medium-chain triglycerides (MCT) are hydrolyzed and absorbed in the gastrointestinal system differently (7). LCT is absorbed via the intestinal lymphatic ducts and transported in chylomicrons through the thoracic duct into the systemic circulation. In contrast, MCT is readily hydrolyzed to medium-chain fatty acids (MCFA) by lingual

E-mail: kuwahata@kpu.ac.jp and gastric lipases. MCFA is transported directly to the liver via the portal vein. Compared with dietary LCT intake, intake of MCT results in increased energy expenditure in human subjects $(8-12)$. Previous studies have thus reported that body fat accumulation is suppressed by dietary MCT intake $(12,13)$.

Although the effects of MCT on lipid metabolism in both healthy $(8-10,13)$ and obese subjects $(8,11-13)$ have been reported, whether MCT can improve lipid metabolism in malnourished subjects remains unclear. The present study examined the effects of dietary MCT on hepatic lipid deposition in rats fed low-protein diet, and then investigated the expression of genes encoding proteins involved in liver fatty acid oxidation.

\section{MATERIALS AND METHODS}

Animal experiments. Animal facilities and protocols were reviewed and approved by the Institutional Animal Care and Use Committee of Kyoto Prefectural University. Male weaning Wistar rats (age, $3 \mathrm{wk}$ ) were purchased from CLEA Japan, Inc. (Osaka, Japan) and housed in individual metabolic cages in a temperatureand humidity-controlled room with a 12-h light/dark cycle (lights on 08:00-20:00 h). After an acclimation period of $5 \mathrm{~d}$, rats were divided into 4 groups as follows: 
the CP group was fed a control diet containing normal levels of protein $(20 \mathrm{~g}$ casein/100 g diet), with or without MCT; and the LP group was fed a low-protein diet (3 g casein/100 g diet), with or without MCT. Compositions of the test diets are shown in Table 1. During the experimental period, rats in the CP-MCT $(n=10)$, $\mathrm{CP}+\mathrm{MCT}(n=10)$ and LP+MCT $(n=10)$ groups were pair-fed each test diet based on the mean amount of diet consumed ad libitum on the previous day by rats in the LP-MCT group $(n=11)$ in order to equalize the total food intake of each group. After $30 \mathrm{~d}$ of dietary treatment, rats were anesthetized with diethyl ether. Blood was drawn and centrifuged to separate plasma. Livers were rapidly removed and weighed. For Oil-Red O staining, pieces of liver were fixed in $10 \%$ formalin solution. Plasma and liver samples were stored at $-70^{\circ} \mathrm{C}$ until analysis.

Measurement of respiratory quotient. After $4 \mathrm{wk}$ of supplementation with each test diet, the respiratory quotient (RQ) was analyzed. Oxygen $\left(\mathrm{O}_{2}\right)$ consumption and carbon dioxide $\left(\mathrm{CO}_{2}\right)$ production were measured by indirect calorimetry using an open-circuit calorimetry system (Oxymax; Columbus Instruments, Columbus, $\mathrm{OH})$. The data collection program was set at an airflow rate of $2.0 \mathrm{~L} / \mathrm{min}$ and a measurement period of $15 \mathrm{~s}$. RQ is calculated as the volume of $\mathrm{CO}_{2}$ produced divided by the volume of $\mathrm{O}_{2}$ consumed. Results of $\mathrm{O}_{2}$ consumption and RQ showed data for $3 \mathrm{~h} \mathrm{(08:00-11:00} \mathrm{h),} 21 \mathrm{~h}$ after providing the test diet.

Analysis of blood chemistry and hepatic triglyceride content. Plasma concentrations of total protein, albumin, total cholesterol and total ketone body were measured using the TP-L, BCG-L, TCHO-L and ketone-T kit (Cerotec Co., Sapporo, Japan), respectively. Samples were analyzed using a CL-8000 autoanalyzer (Shimadzu Co., Kyoto, Japan). Plasma concentration of triglycerides was measured using the triglyceride-E test (Wako Pure Chemical Industries, Ltd., Osaka, Japan).

To determine the concentration of hepatic triglycerides, livers were homogenized in 4 volumes of saline using a Potter homogenizer. The homogenate was mixed with 5 volumes of 2-propanol, shaken for $10 \mathrm{~min}$, and centrifuged at 3,000 rpm for $10 \mathrm{~min}$. The upper layer was collected and assayed using the triglyceride-E test. Values were calculated as $\mathrm{mg} / \mathrm{g}$ of wet tis- sue.

Oil-Red O staining. Frozen sections of formalin-fixed liver $(3 \mu \mathrm{m})$ were stained with Oil-Red $\mathrm{O}$ and counterstained with hematoxylin. Sections were imaged using a microscope (Olympus Co., Tokyo, Japan).

Preparation of total RNA and quantitative real-time polymerase chain reaction. Total RNA was extracted using the ISOGEN system (Nippon Gene, Tokyo, Japan) according to the manufacturer's protocol. First-strand complementary DNA was synthesized using M-MLV reverse transcriptase (Invitrogen Corp., Carlsbad, CA). Real-time polymerase chain reaction (PCR) (DNA Engine Opticon, Bio-Rad, Hercules, CA) was performed using SYBR Premix Ex Taq (Perfect Real Time) (TaKaRa Bio Inc., Shiga, Japan). The specific primers used for real-time PCR are shown in Table 2. The mRNA levels were normalized to the level of $\beta$-actin mRNA.

Statistical analysis. Data are expressed as mean \pm SE. Statistical analysis for multiple comparisons was performed using two-way analysis of variance (ANOVA), and individual groups were compared by the TukeyKramer post hoc test. Data analysis was performed using Statcel2 software (Oms Publishing Inc., Tokyo, Japan) and considered statistically significant at values of $p<0.05$.

Table 1. Composition of experimental diets: $\mathrm{CP}-\mathrm{MCT}$, $\mathrm{CP}+\mathrm{MCT}$, LP-MCT and LP+MCT.

$\mathrm{CP}-\mathrm{MCT} \mathrm{CP}+\mathrm{MCT} \quad \mathrm{LP}-\mathrm{MCT} \quad \mathrm{LP}+\mathrm{MCT}$

\begin{tabular}{|c|c|c|c|c|}
\hline \multirow[b]{2}{*}{ Casein } & \multicolumn{4}{|c|}{$\mathrm{g} / 100 \mathrm{~g}$} \\
\hline & 20.3 & 20.2 & 3.0 & 3.0 \\
\hline Cornstarch & 44.8 & 44.5 & 44.8 & 44.5 \\
\hline Sucrose & 23.4 & 23.2 & 40.7 & 40.4 \\
\hline Soybean oil & 5.1 & 1.3 & 5.1 & 1.3 \\
\hline MCT powder ${ }^{1}$ & 0 & 4.3 & 0 & 4.3 \\
\hline Cellulose & 1.9 & 1.9 & 1.9 & 1.9 \\
\hline Mineral mix ${ }^{2}$ & 3.6 & 3.5 & 3.6 & 3.5 \\
\hline Vitamin $\operatorname{mix}^{2}$ & 1.0 & 1.0 & 1.0 & 1.0 \\
\hline Energy $(\mathrm{kJ} / \mathrm{g})$ & 14.3 & 14.2 & 14.3 & 14.2 \\
\hline
\end{tabular}

${ }^{1}$ MCT powder ${ }^{\circledR}$ (Nisshin Oillio Ltd., Tokyo, Japan) (g/ $100 \mathrm{~g})$ : MCT, 75.1; carbohydrate, 23.7; ash, 0.1; water, 1.1 .

${ }^{2}$ Based on AIN-76 mixture.

Table 2. Sequences of primers used for real-time RT-PCR.

\begin{tabular}{lll}
\hline & \multicolumn{1}{c}{ Sense primer } & \multicolumn{1}{c}{ Antisense primer } \\
\hline CPT1a (NM_031559) & TCGTCGCACATTAGACCGTGAGGAA & TCTTCCCCAGGGATCCGGGAAGTAT \\
CACT (NM_053965) & ACCCCTGGAGAACGGATCAAATGCT & AAGCCACGGATCCCAAACTCCTGAT \\
CPT2 (NM_012930) & TAGCCGAGGACGGCACTGCT & GCAGGCTGGCTCTGGGGAGT \\
LCAD (NM_012819) & AGGATTTATTAAGGGCAAGAAGCTA & GAGCTCTTGCATGAGGTAGTAGAAG \\
MCAD (NM_016986) & GGTGTACAGGGGTGCAGACTGCTAT & GTCACGCAGTAGGCACACATCATCG \\
ACO (J02752) & AGTTACTTGTCTTACCTCCAGGCTT & ATAGCTGAGGGCTCTCCATATACTT \\
$\beta$-Actin (NM_031144) & CCACACCCGCCACCAGTTCG & TAGGGCGGCCCACGATGGAG \\
\hline
\end{tabular}

The GenBank accession numbers are indicated in brackets. The primer sequences are written from $5^{\prime}$ to $3^{\prime}$ end. CPT1a, carnitine palmitoyltransferase 1a; CACT, carnitine-acylcarnitine translocase; CPT2, carnitine palmitoyltransferase 2; LCAD, long-chain acyl-CoA dehydrogenase; MCAD, medium-chain acyl-CoA dehydrogenase; ACO, acyl-CoA oxidase. 


\section{RESULTS}

Characteristics of experimental animals

No significant differences in food intake were seen among the experimental groups (CP-MCT, $9.6 \mathrm{~g} / \mathrm{d}$; $\mathrm{CP}+\mathrm{MCT}, 9.6 \mathrm{~g} / \mathrm{d}$; LP-MCT, 9.3 $\pm 0.1 \mathrm{~g} / \mathrm{d}$; LP+MCT, $9.5 \mathrm{~g} / \mathrm{d})$. Body weight during consumption of experimental diets increased slightly in rats fed CP diets (Fig. 1). Conversely, rats fed LP diets had a slight decrease in body weight (Fig. 1). After $4 \mathrm{wk}$ of supplementation with each test diet, no significant differences in $\mathrm{O}_{2}$ consumption during the fasting period were seen among the experimental groups (Fig. 2A). On the other hand, $\mathrm{RQ}$ was higher in the LP-MCT group than in other groups (Fig. 2B).

Final body weight, plasma concentration of total protein, albumin and total cholesterol were significantly lower in rats fed LP diets than in rats fed CP diets (Table

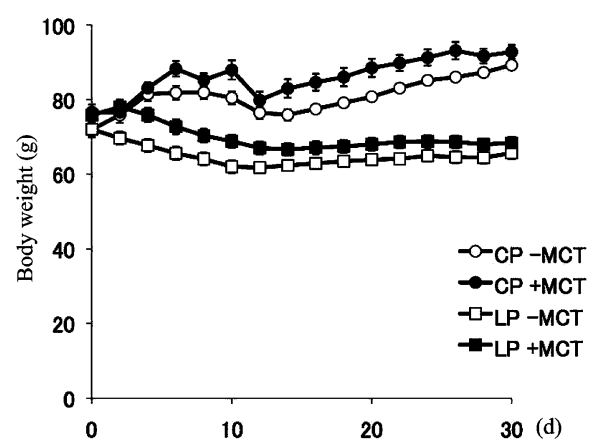

Fig. 1. Rat body weights during the consumption of experimental diets. Rats were divided into 4 groups as follows: the CP groups, fed a control diet ( $20 \mathrm{~g}$ casein/ $100 \mathrm{~g}$ diet), with or without MCT (CP+MCT, CP-MCT); and the LP groups, fed a low-protein diet (3 g casein/ $100 \mathrm{~g}$ diet), with or without MCT (LP+MCT, LP-MCT). Rats in the $\mathrm{CP}-\mathrm{MCT}, \mathrm{CP}+\mathrm{MCT}$ and $\mathrm{LP}+\mathrm{MCT}$ groups were pair-fed their respective test diet based on the mean amount of diet consumed on the previous day by the $\mathrm{LP}-\mathrm{MCT}$ group. Values are expressed as means \pm SE $(n=10 \mathrm{CP}-\mathrm{MCT}, n=10 \mathrm{CP}+\mathrm{MCT}, n=11 \mathrm{LP}-\mathrm{MCT}$, $n=10 \mathrm{LP}+\mathrm{MCT})$.
3). No significant differences were evident in plasma triglyceride levels among groups (Table 3). Relative liver weight was higher in the LP-MCT group than in other groups (Table 3). Plasma concentration of total ketone body was lower in the LP-MCT group than the $\mathrm{CP}-$ MCT group, but similar in the $\mathrm{LP}+\mathrm{MCT}$ and $\mathrm{CP}+\mathrm{MCT}$ groups (Table 3).

Hepatic triglyceride content and Oil-Red O staining

Dietary protein $(p<0.001)$ and lipid $(p=0.003)$ showed significant effects on hepatic triglyceride content, along with a significant interaction $(p=0.012)$.
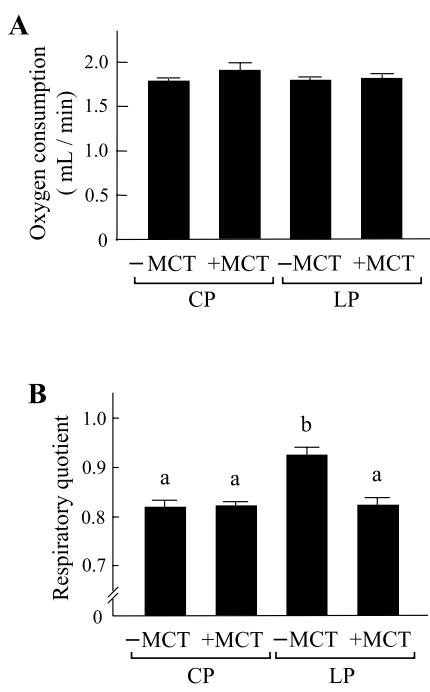

Fig. 2. Oxygen consumption (A) and respiratory quotient (RQ) (B) of rats in the fasting period. Rats were maintained for $4 \mathrm{wk}$ with each test diet. On the day before analysis, individual rats were placed in the metabolic chamber and supplied with their respective diet. Gas analysis began $21 \mathrm{~h}$ after the diet was supplied. Data collection was performed for $3 \mathrm{~h}$. Values are expressed as means \pm SE $(n=6)$. (B) Dietary protein and lipid were significant factors, $p<0.001$ and $p<0.05$, respectively (two-way ANOVA) with a significant interaction, $p<0.001$. Groups that do not share a letter are significantly different, $p<0.05$, by Tukey-Kramer post hoc test.

Table 3. Body weight, liver weight and plasma indexes in rats fed experimental diets.

\begin{tabular}{|c|c|c|c|c|c|c|c|}
\hline & \multirow{2}{*}{$\mathrm{CP}-\mathrm{MCT}$} & \multirow{2}{*}{$\mathrm{CP}+\mathrm{MCT}$} & \multirow{2}{*}{$\mathrm{LP}-\mathrm{MCT}$} & \multirow{2}{*}{$\mathrm{LP}+\mathrm{MCT}$} & \multicolumn{3}{|c|}{ Two-way ANOVA } \\
\hline & & & & & Protein $(p)$ & Lipid $(p)$ & Interaction $(p)$ \\
\hline Body weight, $g$ & $89.2 \pm 1.9$ & $92.8 \pm 1.1$ & $65.7 \pm 1.6$ & $68.4 \pm 1.6$ & $<0.001$ & 0.059 & 0.792 \\
\hline Liver weight, $\mathrm{g}$ & $2.37 \pm 0.04^{\mathrm{a}}$ & $2.43 \pm 0.04^{\mathrm{a}}$ & $2.42 \pm 0.16^{\mathrm{a}}$ & $2.10 \pm 0.08^{\mathrm{a}}$ & 0.163 & 0.180 & $<0.05$ \\
\hline $\mathrm{g} / 100 \mathrm{~g}$ body weight & $2.65 \pm 0.04^{\mathrm{a}}$ & $2.63 \pm 0.03^{\mathrm{a}}$ & $3.66 \pm 0.19^{b}$ & $3.07 \pm 0.09^{\mathrm{a}}$ & $<0.001$ & $<0.05$ & $<0.05$ \\
\hline Blood biochemistry & & & & & & & \\
\hline Total protein, g/dL & $4.9 \pm 0.1$ & $5.3 \pm 0.1$ & $3.7 \pm 0.2$ & $4.0 \pm 0.1$ & $<0.001$ & $<0.05$ & 0.558 \\
\hline Albumin, $\mathrm{g} / \mathrm{dL}$ & $2.6 \pm 0.1$ & $2.4 \pm 0.1$ & $1.6 \pm 0.1$ & $1.8 \pm 0.1$ & $<0.001$ & 0.692 & 0.126 \\
\hline Triglycerides, mg/dL & $49 \pm 5$ & $61 \pm 5$ & $46 \pm 6$ & $52 \pm 4$ & 0.244 & 0.091 & 0.572 \\
\hline Total cholesterol, mg/dL & $81 \pm 4$ & $80 \pm 3$ & $57 \pm 5$ & $56 \pm 2$ & $<0.001$ & 0.878 & 0.969 \\
\hline Total ketone body, $\mu \mathrm{mol} / \mathrm{L}$ & $1,743 \pm 174^{\mathrm{a}}$ & $1,333 \pm 185^{\mathrm{ab}}$ & $267 \pm 74^{\mathrm{c}}$ & $1,024 \pm 125^{\mathrm{b}}$ & $<0.001$ & 0.529 & $<0.001$ \\
\hline
\end{tabular}

Values are expressed as means $\pm \mathrm{SE}(n=10 \mathrm{CP}-\mathrm{MCT}, n=10 \mathrm{CP}+\mathrm{MCT}, n=11 \mathrm{LP}-\mathrm{MCT}, n=10 \mathrm{LP}+\mathrm{MCT})$. Within a row, significantly different values are marked with different superscripts when a significant interaction was observed. 

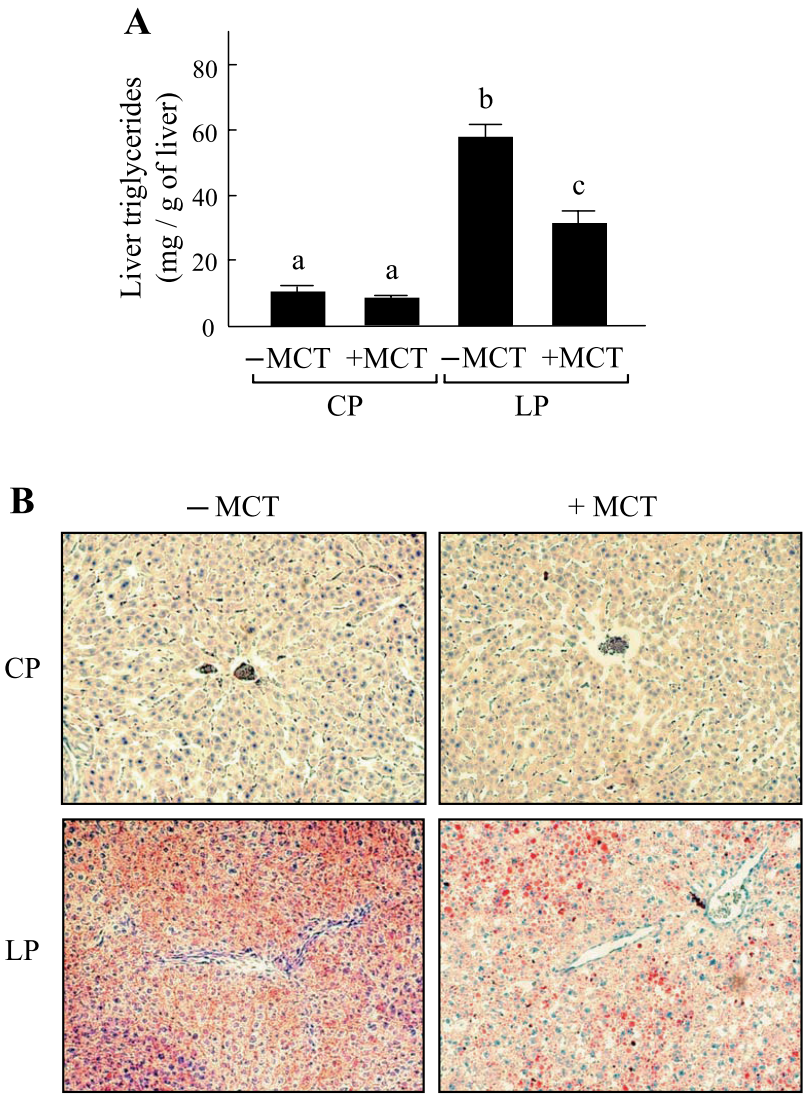

Fig. 3. Liver triglyceride content and Oil-Red $\mathrm{O}$ staining. (A) Triglyceride content was measured in lipid extracts from liver homogenate samples. Values are expressed as means \pm SE $(n=10 \mathrm{CP}-\mathrm{MCT}, n=10 \mathrm{CP}+\mathrm{MCT}, n=11$ $\mathrm{LP}-\mathrm{MCT}, n=10 \mathrm{LP}+\mathrm{MCT}$ ). Within a row, significantly different values are marked with different superscripts when a significant interaction was observed. Dietary protein and lipid were significant factors, $p<0.001$ and $p<0.05$, respectively (two-way ANOVA) with a significant interaction, $p<0.05$. Groups that do not share a letter are significantly different, $p<0.05$, by TukeyKramer post hoc test. (B) Liver sections were stained with Oil-Red $\mathrm{O}$ and counterstained with hematoxylin. Red droplets indicate positive staining for neutral lipid.

Hepatic triglyceride content increased in LP groups compared with CP groups (Fig. 3A), whereas hepatic triglyceride content in the LP+MCT group significantly decreased compared with the LP-MCT group (Fig. 3A). The results of Oil-Red $\mathrm{O}$ staining also showed that obvious triglyceride accumulation was observed in the livers of the LP groups (Fig. 3B). However, intake of MCT caused reduction in low-protein induced hepatic triglyceride accumulation, which was confirmed by Oil-Red $\mathrm{O}$ staining (Fig. 3B).

Levels of mRNAs encoding proteins involved in fatty acid oxidation in livers of rats fed experimental diets

Two-way ANOVA showed a significant effect of dietary lipid $(p=0.002)$, but not of protein $(p=0.362)$ on carnitine palmitoyltransferase (CPT) 1a mRNA level (Fig. 4A). Furthermore, a significant interaction was apparent $(p=0.002)$. A significant effect was seen for dietary protein $(p=0.002)$, but not for lipid $(p=0.118)$
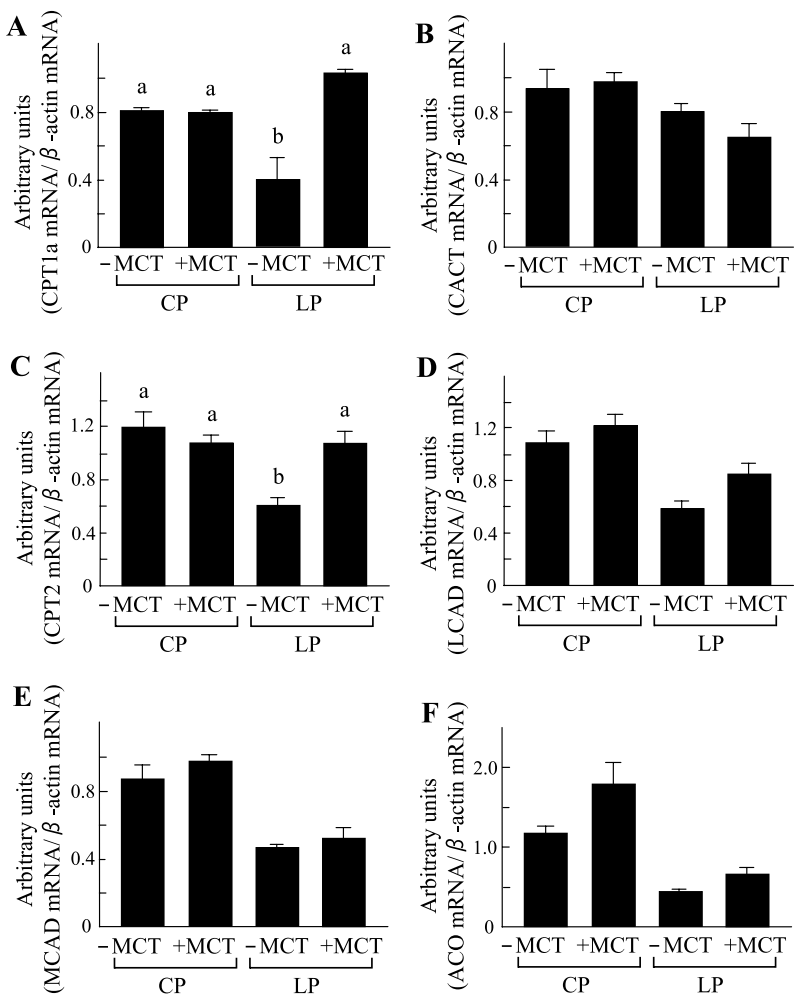

Fig. 4. Effects of dietary protein and lipid on levels of mRNAs encoding proteins involved in fatty acid oxidation in rat liver. Levels of mRNAs encoding CPT1a (A), CACT (B), CPT2 (C), LCAD (D), MCAD (E) and ACO (F) in the liver were measured using real-time PCR. mRNA levels were normalized against $\beta$-actin mRNA level. Values are expressed as means $\pm \mathrm{SE}(n=10 \mathrm{CP}-\mathrm{MCT}$, $n=10 \mathrm{CP}+\mathrm{MCT}, n=11 \mathrm{LP}-\mathrm{MCT}, n=10 \mathrm{LP}+\mathrm{MCT})$. (A) There was a significant effect of dietary lipid $(p<0.05$, two-way ANOVA), but not of protein $(p=0.36)$, and a significant interaction between dietary protein and lipid $(p<0.05)$. (C) There was a significant effect of dietary protein $(p<0.05$, two-way ANOVA), but not of lipid $(p=0.12)$, and a significant interaction between dietary protein and lipid $(p<0.05)$. Groups that do not share a letter are significantly different, $p<0.05$, by TukeyKramer post hoc test.

on CPT2 mRNA level (Fig. 4C). A significant interaction was also seen $(p=0.005)$. Levels of mRNAs encoding CPT1a and CPT2 were significantly decreased in the livers of the LP-MCT group, compared with those in the livers of other groups (Fig. 4A, C).

Two-way ANOVA showed significant effects of dietary protein $(p<0.005)$ on levels of mRNAs encoding carnitine-acylcarnitine translocase (CACT) (Fig. 4B), long-chain acyl-CoA dehydrogenase (LCAD) (Fig. 4D), medium-chain acyl-CoA dehydrogenase (MCAD) (Fig. 4E) and acyl-CoA oxidase (ACO) (Fig. 4F). Dietary lipid had significant effects on levels of mRNAs encoding $\operatorname{LCAD}(p=0.028)$ and ACO $(p=0.007)$, but not on mRNAs encoding CACT $(p=0.353)$ or $\operatorname{MCAD}(p=$ 0.143).

\section{DISCUSSION}

The factors underlying the development of fatty liver 
in protein malnutrition are poorly understood. The present findings suggest that decreased expression of genes encoding proteins involved in fatty acid oxidation is one of the factors underlying the development of fatty liver induced by protein deficiency. The mitochondrial outer membrane enzyme CPT1a is known to play a pivotal role in the regulation of $\beta$-oxidation in the liver (14). Levels of CPT1a protein change during development and in response to nutritional status. Fatty liver induced by protein deficiency is a common symptom in young children rather than adults (1-5). It was reported that the level of hepatic CPT1a was high during the entire suckling period (15). After weaning, the level of hepatic CPT1a decreased in rats fed a high-carbohydrate diet (15). However, levels of CPT1a in weaning rats fed the high-carbohydrate diet were double the levels seen in adult rat livers (15). These developmental changes in CPT1a protein were closely related to the changes in its mRNA levels (15). A moderate increase in CPT1a is sufficient to stimulate fatty acid oxidation and substantially reduce hepatic triglyceride accumulation in rats (16). In the present study, both the decreased level of hepatic CPT1a mRNA and development of fatty liver were observed in growing rats fed low-protein diets. The influence that a decrease in CPT1a mRNA exerts on lipid metabolism may be greater in growing rats than adult rats. On the other hand, it is well known that CPT1a is tightly regulated by its physiological inhibitor malonyl-CoA (17). A recent study suggests that malonyl-CoA inhibits the CPT1a activity by interfering with the binding of carnitine (18). In the present study, we can not exclude the possibility that intake of a low-protein diet influences malonyl-CoA levels.

As MCFA can cross the mitochondrial membrane for oxidation via carnitine-independent mechanisms (7), hepatic triglyceride deposition might be attenuated in the LP+MCT group, compared with the LP-MCT group. Accelerated $\beta$-oxidation produces excess acetylCoA. Much of this acetyl-CoA will be converted into ketone bodies. In the present study, decreased RQ and increased plasma ketone bodies were observed in the $\mathrm{LP}+\mathrm{MCT}$ group, compared with the LP-MCT group. In future studies, direct measurements of $\beta$-oxidation in the LP+MCT group will be important.

In the present study, sucrose was used to replace calories lost by eliminating protein in the low-protein diets. High-sucrose diets have been shown to affect hepatic lipid metabolism (19-22). Furthermore, a recent study suggests that fructose, not glucose, is the primary cause of hepatic abnormality after chronic high-sucrose ingestion (22). Sucrose content in the low-protein diets in the present study was $40 \%$, while most high-sucrose diets in previous studies contained $65-70 \%$ sucrose (19-22). We can not, however, exclude the possibility that intake of sucrose influenced hepatic triglyceride deposition in the present study.

Decreased expression of the mRNAs encoding CPT1a and CPT2 caused by feeding the low-protein diet was attenuated by MCT supplementation. Peroxisome prolif- erator-activated receptor $\alpha(\operatorname{PPAR} \alpha)$ is known as an important factor that transcriptionally activates numerous genes participating in fatty acid oxidation (23-25). Previous studies have reported that PPAR $\alpha$ null mice developed marked hepatic steatosis when maintained under starvation conditions (23) or with methionine- and choline-deficient diets (24). Although both MCAD and ACO genes are the target genes of PPAR $\alpha$ as well as CPT1a and CPT2 (25), expression levels of these mRNAs did not show differences in livers of the LP-MCT and LP+MCT groups. Factors other than $\operatorname{PPAR} \alpha$ might be important to regulate the gene expression of CPT1a and CPT2 by MCT supplementation. Furthermore, MCFA is metabolized via CPT-independent mechanisms (7). Controlling the expression of mRNAs encoding protein involved in the carnitine cycle is not directly due to MCT stimulation, and other factors that are influenced by MCT supplementation might be important.

Previous studies in well-nourished rodents have reported that long-term feeding with MCFA attenuates the accumulation of body fat, but induces triglyceride accumulation in the liver (26-28). The hepatic triglyceride accumulation induced by dietary MCFA was remarkable under sufficient energy intake (26). In the present study, no difference in hepatic triglyceride levels was seen between the $\mathrm{CP}-\mathrm{MCT}$ and $\mathrm{CP}+\mathrm{MCT}$ groups. It seems that hepatic triglyceride accumulation was not observed because rats in the $\mathrm{CP}+\mathrm{MCT}$ group also existed in a state of energy malnutrition. Furthermore, hepatic triglyceride accumulation induced by dietary MCFA has been shown to be caused by enhancing de novo lipogenesis $(27,28)$. In addition to fatty acid oxidation, it will be important to study the effects of MCT on other pathways that influence hepatic lipid deposition, including lipid uptake and de novo lipogenesis, under conditions of protein malnutrition.

In summary, this study indicates that levels of CPT1a mRNA and CPT2 mRNA were decreased in the livers of growing rats with protein malnutrition. In children with severe protein malnutrition, total energy intake may be sufficient, unlike in the rats fed low-protein diets in the present study. However, these findings may explain, at least in part, the mechanisms underlying fat deposition in the livers of children with protein malnutrition. Furthermore, this study suggests that MCT supplementation may be beneficial to prevent fatty liver caused by protein malnutrition in children.

\section{Acknowledgments}

This research was supported in part by a Grant-inAid for Scientific Research (21700763 to M.K.) from Japan Society for the Promotion of Science. The authors are grateful to Dr. Toshiaki Aoyama (The Nisshin Oillio Ltd.) for generously donating MCT powder.

\section{REFERENCES}

1) McLean AE. 1962. Hepatic failure in malnutrition. Lancet 2: 1292-1294.

2) Truswell AS, Hansen JD, Watson CE, Wannenburg P. 
1969. Relation of serum lipids and lipoproteins to fatty liver in kwashiorkor. Am J Clin Nutr 22: 568-576.

3) Flores H, Pak N, Maccioni A, Monckeberg F. 1970. Lipid transport in kwashiorkor. Br J Nutr 24: 1005-1011.

4) Coward WA, Whitehead RG. 1972. Changes in serum $\beta$-lipoprotein concentration during the development of kwashiorkor and in recovery. Br J Nutr 27: 383-394.

5) Badaloo A, Reid M, Soares D, Forrester T, Jahoor F. 2005. Relation between liver fat content and the rate of VLDL apolipoprotein B-100 synthesis in children with protein-energy malnutrition. Am J Clin Nutr 81: 11261132.

6) Badaloo AV, Forrester T, Reid M, Jahoor F. 2006. Lipid kinetic differences between children with kwashiorkor and those with marasmus. Am J Clin Nutr 83: 12831288.

7) Bach AC, Babayan VK. 1982. Medium-chain triglycerides: an update. Am J Clin Nutr 36: 950-962.

8) Scalfi L, Coltorti A, Contaldo F. 1991. Postprandial thermogenesis in lean and obese subjects after meals supplemented with medium-chain and long-chain triglycerides. Am J Clin Nutr 53: 1130-1133.

9) Matsuo T, Matsuo M, Taguchi N, Takeuchi H. 2001. The thermic effect is greater for structured medium- and long-chain triacylglycerols versus long-chain triacylglycerols in healthy young women. Metabolism 50: 125-130.

10) Bendixen H, Flint A, Raben A, Hoy CE, Mu H, Xu X, Bartels EM, Astrup A. 2002. Effect of 3 modified fats and a conventional fat on appetite, energy intake, energy expenditure, and substrate oxidation in healthy men. Am J Clin Nutr 75: 47-56.

11) St-Onge MP, Bourque C, Jones PJH, Ross R, Parsons WE. 2003. Medium- versus long-chain triglycerides for 27 days increases fat oxidation and energy expenditure without resulting in changes in body composition in overweight women. Int J Obes 27: 95-102.

12) St-Onge MP, Ross R, Parsons WD, Jones PJH. 2003. Medium-chain triglycerides increase energy expenditure and decrease adiposity in overweight men. Obes Res 11: 395-402.

13) Tsuji H, Kasai M, Takeuchi H, Nakamura M, Okazaki M, Kondo K. 2001. Dietary medium-chain triacylglycerols suppress accumulation of body fat in a double-blind, controlled trial in healthy men and women. J Nutr 131: 2853-2859.

14) McGarry JD, Brown NF. 1997. The mitochondrial carnitine palmitoyltransferase system. From concept to molecular analysis. Eur J Biochem 244: 1-14.

15) Thumelin S, Esser V, Charvy D, Kolodziej M, Zammit VA, McGarry D, Girard J, Pegorier JP. 1994. Expression of liver carnitine palmitoyltransferase I and II genes during development in the rat. Biochem J 300: 583-587.

16) Stefanovic-Racic M, Perdomo G, Mantell BS, Sipula IJ, Brown NF, O'Doherty RM. 2008. A moderate increase in carnitine palmitoyltransferase 1a activity is sufficient to substantially reduce hepatic triglyceride levels. Am J Physiol Endocrinol Metab 294: E969-E977.
17) McGarry JD, Mannaerts GP, Foster DW. 1977. A possible role for malonyl-CoA in the regulation of hepatic fatty acid oxidation and ketogenesis. J Clin Invest 60: 265270.

18) Lopez-Vinas E, Bentebibbel A, Gurunathan C, Morillas M, de Arriaga D, Serra D, Asins G, Hegardt FG, GomezPuertas P. 2007. Definition by functional and structural analysis of two malonyl-CoA sites in carnitine palmitoyltransferase 1A. J Biol Chem 282: 18212-18224.

19) Song Z, Deaciuc I, Zhou Z, Song M, Chen T, Hill D, McClain CJ. 2007. Involvement of AMP-activated protein kinase in beneficial effects of betaine on highsucrose diet-induced hepatic steatosis. Am J Physiol Gastrointest Liver Physiol 293: G894-G902.

20) Huang W, Dedousis N, O'Doherty RM. 2007. Hepatic steatosis and plasma dyslipidemia induced by a highsucrose diet are corrected by an acute leptin infusion. $J$ Appl Physiol 102: 2260-2265.

21) Deaciuc IV, Song Z, Peng X, Barve SS, Song M, He Q, Knudsen TB, Singh AV, McClain CJ. 2008. Genome-wide transcriptome expression in the liver of a mouse model of high carbohydrate diet-induced liver steatosis and its significance for the disease. Hepatol Int 2: 39-49.

22) Kawasaki T, Igarashi K, Koeda T, Sugimoto K, Nakagawa K, Hayashi S, Yamaji R, Inui H, Fukusato T, Yamanouchi T. 2009. Rats fed fructose-enriched diets have characteristics of nonalcoholic hepatic steatosis. J Nutr 139: 2067-2071.

23) Kersten S, Seydoux J, Peters JM, Gonzalez FJ, Desvergne B, Wahli W. 1999. Peroxisome proliferator-activated receptor $\alpha$ mediates the adaptive response to fasting. $J$ Clin Invest 103: 1489-1498.

24) Ip E, Farrell GC, Robertson G, Hall P, Kirsch R, Leclercq I. 2003. Central role of $\operatorname{PPAR} \alpha$-dependent hepatic lipid turnover in dietary steatohepatitis in mice. Hepatology 38: 123-132.

25) Aoyama T, Peters JM, Iritani N, Nakajima T, Furihata K, Hashimoto T, Gonzalez FJ. 1998. Altered constitutive expression of fatty acid-metabolizing enzymes in mice lacking the peroxisome proliferator-activated receptor $\alpha$ $(\operatorname{PPAR} \alpha)$. J Biol Chem 273: 5678-5684.

26) Matsuo T, Takeuchi H. 2004. Effects of structured medium- and long-chain triacylglycerols in diets with various levels of fat on body fat accumulation in rats. $\mathrm{Br}$ J Nutr 91: 219-225.

27) Shinohara H, Ogawa A, Kasai M, Aoyama T. 2005. Effect of randomly interesterified triacylglycerols containing medium- and long-chain fatty acids on energy expenditure and hepatic fatty acid metabolism in rats. Biosci Biotechnol Biochem 69: 1811-1818.

28) Turner N, Hariharan K, TidAng J, Frangioudakis G, Beale SM, Wright LE, Zeng XY, Leslie SJ, Li JY, Kraegen EW, Cooney GJ, Ye JM. 2009. Enhancement of muscle mitochondrial oxidative capacity and alterations in insulin action are lipid species dependent: potent tissuespecific effects of medium-chain fatty acids. Diabetes $\mathbf{5 8}$ : 2547-2554. 